\title{
A Longitudinal Study of Violent Behavior in a Psychosis-Risk Cohort
}

\author{
Gary Brucato', Paul S Appelbaum', Jeffrey A Lieberman', Melanie M Wall', Tianshu Feng', \\ Michael D Masucci', Rebecca Altschuler' and Ragy R Girgis*,I \\ 'The New York State Psychiatric Institute, Columbia University Medical Center, New York, NY, USA
}

\begin{abstract}
There is a lack of insight into the relationships between violent ideation, violent behavior, and early, particularly attenuated, psychosis. Our aims were to examine the relationships between baseline violent behavior and violent ideation and outcome violent behavior and conversion to psychosis in at-risk individuals. We longitudinally assessed 200 individuals at clinical high risk for psychosis for violent ideation and violent behavior using the Structured Interview for Psychosis-Risk Syndromes (SIPS), and rated these according to MacArthur Community Violence categories. Fifty-six individuals (28\%) reported violent ideation at baseline, 12 (6\%) reported violent behavior within 6 months pre-baseline, and 8 (4\%) committed acts of violence during the follow-up time period. Information about violent ideation was obtained only by indirect, but not direct, inquiry about violent ideation. Both violent ideation and violent behavior at baseline significantly predicted violent behavior ( $R R=13.9, p=0.001 ; R R=8.3, p=0.003$, respectively) during follow-up, as well as a diagnosis of psychosis $(R R=2.3$ and 2.4 , respectively; both $p<0.001)$, independent of more than 40 clinical and demographic variables. The targets of the subjects' violent ideation at baseline were completely different than their subsequent targets of violent behavior. Violent behavior occurred within 7 days (SD 35 days) of a diagnosis of syndromal psychosis. These data suggest that checking carefully for violent ideation and behavior in clinical high-risk patients is essential, as these have predictive value for conversion to psychosis and likelihood of violence in the future.

Neuropsychopharmacology (20I8) 43, 264-27I; doi:I0.1038/npp.2017.15I; published online 9 August 2017
\end{abstract}

\section{INTRODUCTION}

Although most mentally ill individuals are not dangerous and most violence is committed by asymptomatic persons, some evidence suggests that positive symptoms in the context of psychotic illness, such as delusions and hallucinations, are related to violent behavior (Coid et al, 2013; Keers et al, 2014; McNiel et al, 2000). Non-adherence with medications (Elbogen et al, 2006; Yesavage, 1982) and poor insight (Buckley et al, 2004) have been shown to mediate this relationship. Other research suggests that alcohol (Rasanen et al, 1998) or drug abuse (Elbogen and Johnson, 2009; Swartz et al, 1998) is the key mediating factor, and may account for more of the risk than psychosis (Fazel et al, 2009). This was supported by the landmark MacArthur Violence Risk Assessment Study (MVRAS), which identified substance use as a substantial and significant factor affecting risk of violence in psychotic populations (Appelbaum et al, 2000; Steadman et al, 1998).

Prior studies suggest that the first episode of a psychotic illness is a time of particular risk for violent behavior

* Correspondence: Dr RR Girgis, New York State Psychiatric Institute, Columbia University Medical Center, 1051 Riverside Drive, Unit 31 , New York, NY I0032, USA, Tel: + 646774 5553, Fax: + I 646 7745237, E-mail: rg2290@columbia.edu

Received 24 April 2017; revised 12 June 2017; accepted 7 July 2017; accepted article preview online 26 July 2017
(Langeveld et al, 2014; Large and Nielssen, 2011; Nielssen and Large, 2010). The first-episode literature suggests that not only does younger age increase risk of violence, but that the prevalence of violent behavior in people with psychotic disorders peaks in the first episode of psychosis, and then quickly declines, although it remains above the rate in the unaffected population (Langeveld et al, 2014; Large and Nielssen, 2011; Nielssen and Large, 2010). The possibility that violence risk might increase as an individual at high risk for psychosis approaches a diagnosis of psychosis may also be supported by evidence that more prominent psychotic symptoms and less insight increase the risk of violent acts (Buckley et al, 2004; Swartz et al, 1998).

Our lack of understanding of violence risk in psychosis, particularly during attenuated or early phases of psychosis, reflects that prior studies were performed in already psychotic individuals, possibly confounded by medication treatment, chronicity, and other factors (Cannon et al, 2007; McGorry et al, 2001; Miller et al, 2003), and/or did not possess longitudinal components or were retrospective. Additionally, the presumed antecedents of violent behavior (ie, violent ideation) were not measured in the majority of studies, possibly partly related to the lack of an available rating scale for violent ideation. These factors complicate the disentangling of links between violent behavior and psychotic symptoms, and preclude an examination of the temporal progression from violent ideation to violent behavior. 
We enrolled 200 individuals at clinical high risk (CHR) for psychosis, measured violent ideation, violent behavior, and symptoms at baseline, and followed them for up to 2 years. Our specific aims were to: (1) identify baseline factors that predict future violent behavior and (2) examine the ability of baseline violent ideation and violent behavior to predict a future diagnosis of psychosis. Our hypotheses were that baseline violent behavior and violent ideation would predict future violent behavior, and that baseline violent ideation and violent behavior would predict a subsequent diagnosis of psychosis, all independent of demographic or other clinical variables, including positive psychotic symptoms.

\section{MATERIALS AND METHODS}

\section{Subjects}

A cohort of 200 help-seeking individuals at CHR for psychosis, aged 13-30, was ascertained using the Structured Interview for Psychosis Risk Symptoms (SIPS) (Miller et al, 2003) between 2003 and 2016, and followed for approximately 2 years. Subjects were enrolled if they met criteria for at least one of the following psychosis-risk syndromes, as defined by the SIPS (Miller et al, 2003): (1) Attenuated Positive Symptom Psychosis-Risk Syndrome (APSS); (2) Genetic Risk and Deterioration Psychosis-Risk Syndrome (GRDS); and/or (3) Brief Intermittent Psychotic PsychosisRisk Syndrome (BIPS). Approval from the NYSPI Institutional Review Board was obtained before any procedures were undertaken, and all subjects provided written informed consent. Individuals less than 18 years old provided written informed assent and at least one parent provided written informed consent.

\section{Measures}

Information on violent ideation and violent behavior was obtained at baseline, and on violent behavior at every followup, via the SIPS completed with the patient on his or her own and accompanying clinical interview with the patient. Clinical information obtained from the treating research psychiatrist or therapist, and parents were used to confirm or clarify ambiguous information. If a positive report was given, detailed information about the ideation or behavior, such as target, imagined method and setting, perceived likelihood of acting, precipitating factors and/or symptoms, and, for ideation alone, whether it was experienced as intrusive or ego-syntonic. Individuals who endorsed significant risk for violence during the interview were evaluated and clinically treated.

The categories in the MacArthur Community Violence Interview (MCVI) (Steadman et al, 1998; Swanson et al, 2006) were used to categorize violent behavior as any assault using a lethal weapon or resulting in injury, any threat with a lethal weapon in-hand, or any sexual assault. We also defined other aggressive acts as simple assault without injury (eg, slapping, grabbing) or weapon use. For the baseline assessment of violent behavior and other aggressive acts, this included any such behaviors within the previous 6 months. Outcome data were any violent behavior occurring post-baseline.
Notably, given the lack of availability of rating scales for violent ideation, we took a novel approach by adapting the MacArthur interview to score violent ideation within the same framework as violent behavior, and only at the time of assessment (ie, not in the past 6 months, as with violent behavior).

We defined a third category of non-violent aggression (ideation or behavior) involving acts such as verbal aggression, stalking, property destruction, agitation, etc that did not involve violence towards another person (see the Supplementary Data for more information).

\section{Statistical Analyses}

Descriptive statistics, and mean differences in demographics between individuals with and without violent ideation or violent behavior or between patients who later developed a diagnosis of psychosis and those who did not, were derived using SPSS version 22 (IBM Corporation, 2013). Group differences were evaluated using one-way ANOVAs for continuous variables (eg, SIPS scores) and for categorical variables (eg, DSM diagnosis) using $\chi^{2}$ tests, or Fisher's exact test where warranted by low cell counts. We evaluated the relationships between baseline violent ideation and violent behavior and violence during the follow-up period or a diagnosis of psychosis using logistic regression. We controlled for variables of interest identified in previous analyses and others that were identified as potentially clinically relevant. $p<0.05$ was used to determine significance.

\section{RESULTS}

\section{Baseline Demographics and Clinical Variables}

The sample of 200 CHR participants was diverse in terms of both race and ethnicity, young, and primarily male. Sixty participants (30\%) developed a diagnosis of psychosis during the follow-up period. All demographic and clinical data are summarized in Table 1 and Supplementary Table S1. Additional demographic and clinical information on this sample has previously been published (Brucato et al, in press). The mean time of follow-up was $12.15 \pm$ 12.12 months.

\section{Baseline Violent Ideation and Behavior, Other Aggressive Acts, and Non-Violent Aggression}

As in Table 2, violent ideation was reported by 56 (28\%) participants at baseline. Violent behavior within 6 months prior to baseline was noted in 12 participants. Other aggressive acts and non-violent aggression were less common (see Supplementary Table S2 for additional information, including on types and targets of ideation and behavior).

\section{Violent Behavior During the Follow-Up Time Period}

Eight individuals (4\%) engaged in an act of violence during the follow-up period. Committing an act of violence during the follow-up period was significantly related to baseline violent ideation $(\mathrm{RR}=13.9(\mathrm{CI}=1.8-113.0))$ and baseline violent behavior $(\mathrm{RR}=8.3(\mathrm{CI}=2.2-30.3))$. Importantly, 
Table I Clinical and Demographic Characteristics

\begin{tabular}{|c|c|c|}
\hline \multirow[t]{3}{*}{ Age at baseline (years) } & \multicolumn{2}{|c|}{ Total $n=200$} \\
\hline & Mean & SD \\
\hline & $\begin{array}{l}20.12 \\
\text { Count }\end{array}$ & $\begin{array}{c}3.86 \\
\%\end{array}$ \\
\hline \multicolumn{3}{|l|}{ Race } \\
\hline Caucasian & 91 & 45.5 \\
\hline Black/African American & 44 & 22 \\
\hline Asian/Pacific Islander & 15 & 7.5 \\
\hline More than one race & 50 & 25 \\
\hline \multicolumn{3}{|l|}{ Race binary } \\
\hline Caucasian & 91 & 45.5 \\
\hline Not Caucasian & 109 & 54.5 \\
\hline \multicolumn{3}{|l|}{ Ethnicity } \\
\hline Not Hispanic or Latino & 138 & 69 \\
\hline Hispanic or Latino & 62 & 31 \\
\hline \multicolumn{3}{|l|}{ Gender } \\
\hline Male & 144 & 72 \\
\hline Female & 56 & 28 \\
\hline \multicolumn{3}{|l|}{ Medication status } \\
\hline None & 138 & 69 \\
\hline Neuroleptics & 15 & 7.5 \\
\hline Antidepressants & 28 & 14 \\
\hline Both & 19 & 9.5 \\
\hline GRDS & 8 & 4.2 \\
\hline SPD at baseline & 114 & 57 \\
\hline Baseline suicidal ideation & 13 & 6.5 \\
\hline Baseline suicidal behavior & 5 & 2.5 \\
\hline Non-sexual trauma & 30 & 15 \\
\hline Sexual trauma & 21 & 10.5 \\
\hline Any trauma & 47 & 23.5 \\
\hline SCID diagnoses at baseline & Total $n=188$ & $\%$ \\
\hline Any lifetime axis I disorder at baseline & 148 & 78.7 \\
\hline Lifetime bipolar I, 2 or NOS & 14 & 7.4 \\
\hline Lifetime MDD, depression NOS, or dysthymia & 100 & 53.2 \\
\hline Any lifetime anxiety disorder & 94 & 50 \\
\hline Any past substance use disorder & 42 & 22.3 \\
\hline Any lifetime eating disorder & 5 & 2.7 \\
\hline
\end{tabular}

neither non-violent aggression nor other aggressive acts at baseline was related to violent behavior at follow-up.

In addition to calculating relative risks, we performed logistic regression to further determine the relationships between baseline violent behavior and violent ideation, and violent behavior during the follow-up period. Before analyzing our model, we compared all available baseline demographic and clinical factors (Table 1 and
Supplementary Table S1), including other aggressive acts and non-violent aggression, between individuals who did and did not commit violent behavior during the follow-up period, to determine which additional baseline factors to include in the model. The only variables distinguishing those who did and did not commit violent behavior during the follow-up period were the P3/Grandiose Ideas ( $t[14.078]$ $=2.27, n=200, p=0.047)$ and P5/Disorganized Communication $(t[198]=-2.53, n=200, p=0.012)$ scores on the SIPS.

We first performed $\chi^{2}$ analyses to examine differences in baseline violent ideation and baseline violent behavior between individuals who did and did not commit violent behavior during the follow-up period. We found that both violent ideation at baseline $\left(\chi^{2}=14.6, n=200, \mathrm{df}=1\right.$, $p<0.001)$ and violent behavior at baseline $\left(\chi^{2}=14.7\right.$, $n=200, \mathrm{df}=1, p<0.001)$ were significantly associated with violent behavior during the follow-up period.

Using binary logistic regression models, both violent ideation at baseline $(\beta=3.2, \quad p=0.007$; overall model $p=0.001)$ and violent behavior at baseline $(\beta=3.0$, $p=0.004$; overall model $p=0.003$ ) significantly and independently predicted violent behavior during follow-up, even when controlling for P3/Grandiose Ideas and P5/Disorganized Communication of the SIPS. P5/Disorganized Communication was significant in the models with violent ideation at baseline $(\beta=1.1, p=0.01)$ and baseline violent behavior ( $\beta=1.1, p=0.007)$, and age was significant only in the model with baseline violent behavior $(\beta=-0.3, p<0.05)$. Of note, in these models, sex had a high SE. The results were no different with or without sex included as a factor, so we provide the results for the models without sex.

\section{Additional Information on Violent Acts}

Eight out of 59 individuals who developed a diagnosis of psychosis had baseline violent behavior and six had outcome violent behavior. Four of out 141 individuals who did not develop psychosis had violent behavior at baseline and two had violent behavior at outcome.

Of the six individuals who committed violent behavior during the follow-up period and also developed a diagnosis of psychosis, one acted out approximately 2 months prior to conversion, one at the same time, one approximately 2 weeks after, and three acted out approximately 1 month after. Four of these individuals converted to schizophrenia or schizoaffective disorder, one to bipolar disorder with psychotic features, and one to psychotic disorder not otherwise specified (NOS). The average time between outcome violent behavior and a diagnosis of psychosis being made was 1 week (SD 35 days).

Of the nine patients who committed any violent behavior or other aggressive acts during the follow-up period, five were not taking any medication, two were taking only antipsychotic medications, and two were taking both antipsychotic medications and antidepressant medications. In addition, the mean time between baseline and the act of violence $(N=9)$ was 7.6 months (SD 4.8).

Among all nine acts of violence or other aggressive acts during the follow-up period, five were against a family member or intimate partner, two were against a stranger, one was against a peer/coworker/therapist, and one was 
Table 2 Baseline Frequency of Violent Ideation and Behavior Associated with Follow-up Risk of Violent Behavior and a Diagnosis of Psychosis

Follow-up period ( 2 years)

\begin{tabular}{|c|c|c|c|c|c|c|c|c|c|c|}
\hline & & $\begin{array}{l}\text { Baseline violent ideation } \\
\text { or violent behavior } \\
N=200\end{array}$ & \multicolumn{4}{|c|}{$\begin{array}{c}\text { Violent behavior during follow-up } \\
\text { given baseline violent ideation or } \\
\text { violent behavior }\end{array}$} & \multicolumn{4}{|c|}{$\begin{array}{l}\text { Later diagnosis of psychosis given } \\
\text { baseline violent ideation or } \\
\text { violent behavior }\end{array}$} \\
\hline & $\%$ & Count & Risk \% & Count & $\mathbf{R R}$ & $95 \% \mathrm{Cl}$ & Risk \% & Count & $\mathbf{R R}$ & $95 \% \mathrm{Cl}$ \\
\hline Other aggressive acts & 4.5 & 9 & 0 & 0 & 0 & & 33.3 & 3 & 1.6 & $0.6-4.5$ \\
\hline Non-violent aggression & 10.5 & 21 & 0 & 0 & 0 & & 33.3 & 7 & 1.6 & $0.8-3.3$ \\
\hline None & 57.0 & 114 & 0.9 & । & REF & & 20.2 & 23 & REF & \\
\hline None & 82.0 & 164 & 2.4 & 4 & REF & & 27.4 & 45 & REF & \\
\hline
\end{tabular}

indiscriminate (multiple unrelated people). In no case was the target of the violent act during the follow-up period the same as the target identified at baseline.

Among all nine acts of violence or other aggressive acts during the follow-up period, four involved use of a weapon.

None of the individuals who committed an act of violence during the follow-up period reported using an illicit substance or alcohol at the time of the violent act, and none met criteria for any active substance use disorder at baseline.

\section{Prediction of a Later Diagnosis of Psychosis}

We similarly sought to examine the relationship between baseline violent behavior and baseline violent ideation, and a later diagnosis of psychosis. Similar to the results for violent behavior during the follow-up period, a later diagnosis of psychosis was significantly related to baseline violent ideation $(\mathrm{RR}=2.3 ; \mathrm{CI}=1.5-3.6)$ and baseline violent behavior $(\mathrm{RR}=2.4 ; \mathrm{CI}=1.5-3.9$; Table 2$)$. Neither ideation nor behavior for non-violent aggression or other aggressive acts was related to a later diagnosis of psychosis.

In addition to calculating relative risks, we further examined relationships between baseline violent ideation and violent behavior and a diagnosis of psychosis by performing $\chi^{2}$ analyses to examine differences between those patients diagnosed as psychotic and those not diagnosed on our a priori predictor variables (baseline violent ideation and baseline violent behavior) and on the outcome of violent behavior. Baseline violent ideation $\left(\chi^{2}=10.7, n=200, \mathrm{df}=1\right.$, $p=0.001)$, baseline violent behavior $\left(\chi^{2}=8.5, n=200, \mathrm{df}=1\right.$, $p=0.004)$, and outcome violent behavior $\left(\chi^{2}=8.3, n=200\right.$, $\mathrm{df}=1, p=0.004)$ all occurred to a significantly greater degree in CHR individuals who developed a diagnosis of psychosis compared with CHR individuals who did not. Importantly, neither ideation nor behavior for non-violent aggression or other aggressive acts was different between those CHR individuals who did develop a diagnosis of psychosis, and those who did not.

Using binary logistic regression, and controlling for all available baseline demographic and clinical variables (Table 1 and Supplementary Table S1), including other aggressive acts and non-violent aggression, both violent ideation at baseline $(\beta=1.0, \quad p=0.02$; overall model $p<0.001)$ and violent behavior at baseline $(\beta=2.6$, $p=0.003$; overall model $p<0.001)$ significantly and independently predicted conversion to psychosis, even when controlling for SIPS scores (such as P1/Unusual Thought Content and P5/Disorganized Communication that have been replicated to independently predict conversion to psychosis (Addington et al, 2015)). In the model with baseline violent ideation, race $(\beta=1.1, p=0.009)$, P1/Unusual Thought Content $(\beta=0.7, p=0.006)$, and G2/Dysphoric Mood $(\beta=-0.3, p<0.05)$ were also significant predictors of a diagnosis of psychosis. In the model including baseline violent behavior, race $(\beta=1.1, p=0.008)$ and P1/Unusual Thought Content $(\beta=0.9, p=0.001)$ were also significant predictors of a diagnosis of psychosis.

\section{Sources of Information}

Critical to the identification of patients at increased risk for violent behavior is the means by which information about violent ideation is obtained. While violent behavior data are more directly reported by way of questions such as, 'Have you hurt (or hit or attacked or assaulted or harmed) anybody?', eliciting information about violent ideation is more complex, in particular because individuals with attenuated psychotic symptoms largely appear to consider these ideas intrusive and ego-dystonic. Importantly, none of 
Table 3 Sources of Violent Ideation or Ideation Related to Other Aggressive Acts Reported in this Study

\begin{tabular}{|c|c|c|c|}
\hline & & \multicolumn{2}{|c|}{$\begin{array}{l}\text { Any baseline violent ideation or ideation } \\
\text { related to other aggressive acts }\end{array}$} \\
\hline & & Count & Column $\mathbf{N} \%$ \\
\hline P.I. & Have you felt that you are not in control of your own ideas or thoughts? & 28 & $43.10 \%$ \\
\hline P.2. & $\begin{array}{l}\text { I. Do you ever feel that people around you are thinking about you in a negative } \\
\text { way? } \\
\text { 2. Have you ever found yourself feeling mistrustful or suspicious of other } \\
\text { people? } \\
\text { 3. Do you ever feel that you have to pay close attention to what's going on } \\
\text { around you in order to feel safe? } \\
\text { 4. Do you ever feel like you are being singled out or watched? } \\
\text { 5. Do you ever feel people might be intending to harm you? }\end{array}$ & 8 & $12.30 \%$ \\
\hline P.3. & $\begin{array}{l}\text { I. Do you feel you have special gifts or talents? } \\
\text { 2. Have you ever behaved without regard to painful consequences? For } \\
\text { example, do you ever go on excessive spending stress that you can't afford? } \\
\text { 3. Do people ever tell you that your plans or goals are unrealistic? } \\
\text { 4. Do you ever think of yourself as a famous or particularly important person? } \\
\text { 5. Do you ever feel that you have been chosen by God for a special role? }\end{array}$ & 2 & $3.10 \%$ \\
\hline G.2. & Have you had thoughts of harming anyone else? & 0 & $0 \%$ \\
\hline \multicolumn{2}{|c|}{ Other (non-SIPS) } & 31 & $47.70 \%$ \\
\hline
\end{tabular}

Note: Column percentages do not add up to $100 \%$ because in some cases the same information was elicited from multiple sources (eg, SIPS and interviews).

Table 4 Brief Descriptions of Preempted Violence Using Information Obtained from Sources in Table 3

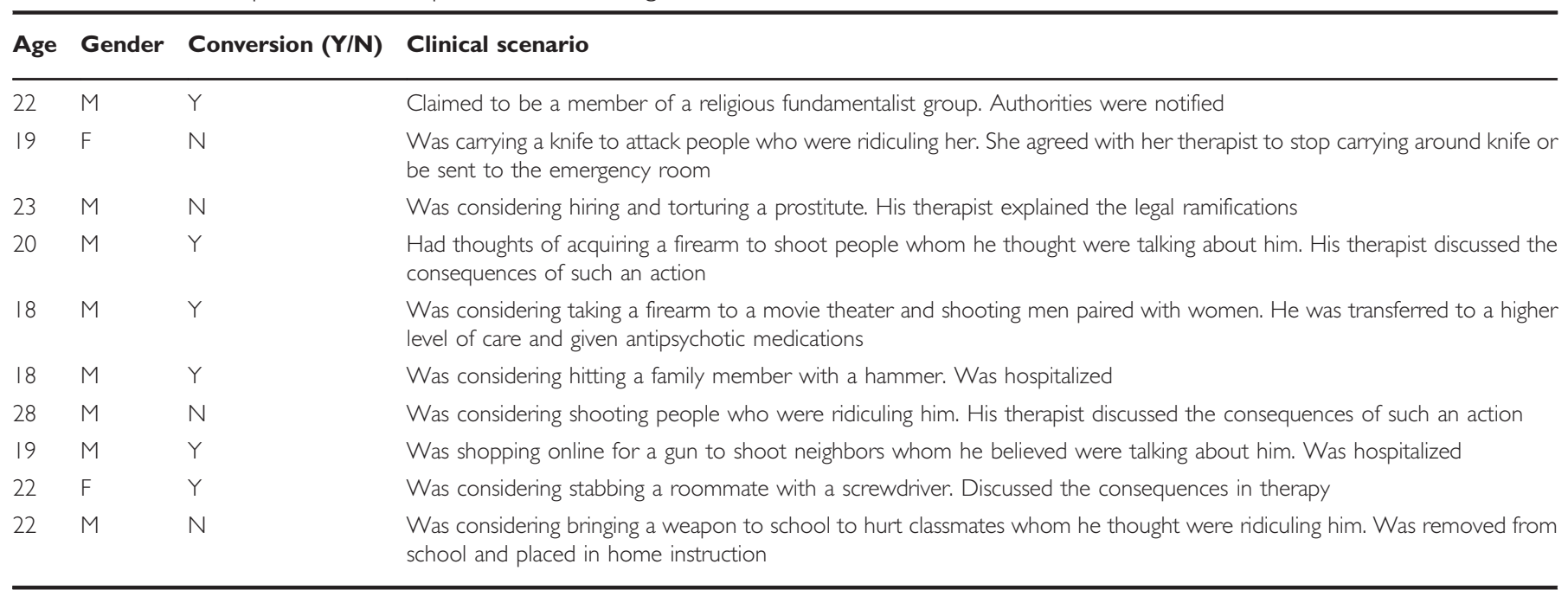

the information on violent ideation was obtained by SIPS item G.2. which specifically queries about violent ideation (Have you had thoughts of harming anyone else?). Table 3 describes the source of all violent ideation or ideation related to other aggressive acts reported in the cohort.

Further, we include in Table 4 the instances of violent ideation elicited from the sources in Table 3 that resulted in action being taken to prevent potentially deadly acts. We also include the pre-emptive actions that were taken.

\section{DISCUSSION}

This longitudinal study of individuals with attenuated and early psychosis provides preliminary information regarding violent ideation and violent behavior. The few previous studies exploring violence among CHR persons have either examined smaller samples; not attempted to identify predictors of violence in a longitudinal study; or examined $\mathrm{CHR}$ individuals for risk factors associated with a diagnosis of psychosis (Broome et al, 2005; Hutton et al, 2012; Marshall et al, 2014).

Twenty-eight percent of participants in our cohort reported violent ideation at baseline, chiefly characterized by thoughts of assault with or without a deadly weapon. Eleven instances of violent ideation (5.5\%) were sexual in nature. Importantly, the entire sample denied violent ideation or ideation related to aggressive acts in response to traditional clinical inquiry (ie, 'Have you had thoughts of 
harming anyone else?' from G2 of the SIPS), but endorsed violent thoughts only when responding to the other portions of the SIPS interview that probed the P1/Unusual Thought Content section regarding thought insertion and any of the inquiries within the P2/Suspiciousness section. It is clear from participants' responses to P1/Unusual Thought Content that they often took literally the pronoun you in traditional risk questions like the one stated above, not perceiving their violent ideation as coming from themselves, but as intruding from some possible external source, with some insight that this was implausible or unlikely. P2/ Suspiciousness questions elicited violent ideation involving having to prepare for self-defense or retaliation against perceived hostility. Notably, Marshall et al (2014) also reported some violent ideation in response to $\mathrm{P} 1 / \mathrm{Unusual}$ Thought Content and P2/Suspiciousness, which supports this finding. These findings are also consistent with the literature on potential relationships between the exposure of young people to violence in media and aggression (Berkowitz, 1984; Browne and Hamilton-Giachritsis, 2005), as well as to findings of the relationship between suicidal ideation and suicide attempts (Klonsky et al, 2016). The current findings have significant implications for the manner in which CHR individuals are evaluated for violent ideation, such that a scale or series of standard questions might be developed that address violent ideation as it is uniquely experienced in the psychosis spectrum.

Second, we found that both violent ideation at baseline and violent behavior in the 6 months prior to baseline were related to subsequent acts of violence and a diagnosis of psychosis in the 2 year follow-up period. These findings are novel. There are several potential reasons for the absence of previous studies of violent ideation in psychosis, including the lack of a rating scale for quantifying violent ideation, the relatively infrequent occurrence of violent behavior in psychosis, and the stigmatizing nature of this topic. Importantly, the relationships among violent ideation at baseline and violent behavior in the 6 months prior to baseline and subsequent acts of violence and a diagnosis of psychosis were unaffected by demographic and other clinical factors, such as trauma history, suicidality, and symptoms. Among the latter, P5/Disorganized Communication was found to have a weaker, but still significant, influence. As this is a measure of attenuated thought disorder, the risk of both violent behavior and a diagnosis of psychosis may be further increased by deterioration of executive or inhibitory functions. Alternatively, violent behavior and clinical deterioration may be more likely in persons struggling to communicate their frustrations and concerns clearly.

It should be emphasized that, despite a high degree of violent ideation in our cohort, violent behavior was very uncommon (only 8 (4\%) compared with $16.6 \%$ in first-episode populations (Large and Nielssen, 2011)) and there were no homicides. This may be related to the treatment provided and potentially preemptive actions taken by our research clinic (Table 4). Interestingly, in no case was the attack's target the one described at baseline, suggesting that assaults were impulsive or unfocused, simply impacting the nearest individuals, as opposed to more organized and methodically plotted violence. Alternatively, it may be that acts were deliberate, but that over the course of an average of 7 to 8 months (the mean time between baseline and act of violence), the target of the patient's aggression shifted.

In all cases, those who developed a diagnosis of psychosis and also displayed violent behavior met criteria for a diagnosis of psychosis within weeks of the violent act, on average 7 days removed ( $\mathrm{SD}=35$ days), suggesting that the violent act itself may have been a manifestation of a diagnosis of psychosis. This supports the finding that many violent acts committed by psychotic individuals occur during their first episodes, prior to initial treatment. This finding can be understood in the context of the finding that violent behavior is in many cases the pathway to diagnosis and treatment in first-episode psychosis (Large and Nielssen, 2011). Of note, in the MVRAS study (Steadman et al, 1998), substance use was identified as a substantial and significant factor affecting risk of violence. In our cohort, no violent act occurred in the context of alcohol or illicit substance use disorder. Further, while literature suggests that nonadherence with medications (Elbogen et al, 2006) may mediate the relationship between psychosis and violence, our study is unable to support any conclusion about the role of medications.

Interpreting our findings in the context of existing literature on violence in psychosis, we propose a theoretical model, whereby individuals in the CHR phase commonly experience intrusive, ego-dystonic violent ideation, with no immediate intention or compulsion to act, and which constitutes an intrinsic trait of psychosis in some people (analogous to suicidal ideation in depression). With a diagnosis of psychosis, influenced to a degree by deterioration in clarity of thought and communication abilities, there is a period of rapid intensification, during which the individual deals with overwhelming emotions and stimuli, and is most at risk to others.

This model and our findings in CHR individuals are supported by findings from the first-episode literature. While most studies were cross-sectional and examined 'aggression,' which was usually a composite of verbal aggression, violent gestures, aggression against objects (eg, throwing furniture), and actual physical aggression, they reveal two main conclusions. First, these articles suggest that the correlates (aka 'risk factors') of violence in a first-episode population are similar to those in a chronic population. Namely, worse clinical state (as measured by symptoms scales or by involuntary hospitalization), higher levels of positive symptoms, substance misuse, male gender, younger age, history of criminality and psychopathy were all related to violent behavior (Chang et al, 2015; Dean et al, 2007; Foley et al, 2007,2005; Langeveld et al, 2014; Large and Nielssen, 2011; Spidel et al, 2010; Steinert et al, 1999; Winsper et al, 2013). Importantly, while in our study we found no such relationships, the same studies reported that previous violent behavior predicted later violent behavior, as did our study (Chang et al, 2015; Dean et al, 2007; Steinert et al, 1999). Importantly, we would not expect hospitalizations, positive symptoms, etc at baseline to predict outcome violent behavior in our population given that our population is an at-risk population and by definition would not have experienced positive symptoms, involuntary hospitalizations, etc at baseline related to the psychosis syndrome as they had not yet had a diagnosis of psychosis. 
Further, similar to our model in which we suggest that the risk of violence peaks around the time of a diagnosis of psychosis (ie, the first episode), the first-episode literature confirms that not only does younger age increase risk of violence, but that the prevalence of violent behavior peaks early in the first episode of psychosis, and then quickly declines (Langeveld et al, 2014; Large and Nielssen, 2011; Nielssen and Large, 2010).

These data suggest that checking carefully for violent ideation and behavior in clinical high-risk patients is essential, as these have predictive value for conversion to psychosis and likelihood of violence in the future. These data also support the potential for links between incipient psychosis and violent behavior and suggest the possibility of identification of a group of patients at elevated risk for violence that might benefit from closer monitoring and rapid treatment interventions.

Importantly, there are several limitations of the current study, including that other potential predictor variables, such as psychopathy, legal involvement, and social/environmental risk factors, were not obtained. In addition, our cohort was help-seeking, and therefore our findings may be inapplicable to the entire population of people in a CHR state, or to a non-clinical population. Further, we did not use scales specifically designed to measure violence, violent ideation, trauma, stress, and other predictor variables, such as social and environmental risk factors, and did not perform urine toxicology tests to confirm that patients were not using substances. Also, critically, that there were only eight patients with outcomes of violent behavior allows the possibility for chance associations and limits the strength of the modeling, given the numerous predictor variables.

In part due to the limitations of this study, these findings pose many questions and require replication. In addition, they support the importance of properly inquiring about violent ideation among persons in the attenuated or burgeoning phases of psychosis; developing an instrument that accurately measures violent ideation and other predictor variables; the need for research aimed at identifying the neurobiological substrates of violent ideation and violent behavior in order to identify treatment targets; and efforts to diminish stigma that may prevent CHR persons from reporting violent ideation, and clinicians from probing for it.

\section{FUNDING AND DISCLOSURE}

JAL has received research funding from and/or is a member of the advisory board of Allon, Alkermes Bioline, GlaxoSmith-Kline Intracellular Therapies, Lilly, Merck, Novartis, Pfizer, Pierre Fabre, Psychogenics, F Hoffman-La Roche, Sunovion, and Targacept. RRG has received research support from Otsuka, Genentech, BioAdvantex, and Allergan. The remaining authors declare no conflict of interest.

\section{ACKNOWLEDGMENTS}

The project was supported by R01MH093398; New York State Office of Mental Hygiene; and K23MH106746.

\section{REFERENCES}

Addington J, Liu L, Buchy L, Cadenhead KS, Cannon TD, Cornblatt BA et al (2015). North American Prodrome Longitudinal Study (NAPLS-2): the prodromal symptoms. J Nerv Ment Dis 203: 328-335.

Appelbaum PS, Robbins PC, Monahan J (2000). Violence and delusions: data from the MacArthur Violence Risk Assessment Study. Am J Psychiatry 157: 566-572.

Berkowitz L (1984). Some effects of thoughts on anti- and prosocial influences of media events: a cognitive-neoassociation analysis. Psychol Bull 95: 410-427.

Broome MR, Woolley JB, Johns LC, Valmaggia LR, Tabraham P, Gafoor R et al (2005). Outreach and support in south London (OASIS): implementation of a clinical service for prodromal psychosis and the at risk mental state. Eur Psychiatry 20: 372-378.

Browne KD, Hamilton-Giachritsis C (2005). The influence of violent media on children and adolescents:a public-health approach. Lancet 365: 702-710.

Brucato G, Masucci MD, Arndt LY, Ben-David S, Colibazzi T, Corcoran CM et al (2017). Baseline demographics, clinical features and predictors of conversion among 200 individuals in a longitudinal prospective psychosis-risk cohort. Psychol Med 47: 1923-1935.

Buckley PF, Hrouda DR, Friedman L, Noffsinger SG, Resnick PJ, Camlin-Shingler K (2004). Insight and its relationship to violent behavior in patients with schizophrenia. Am J Psychiatry 161: 1712-1714.

Cannon TD, Cornblatt B, McGorry P (2007). The empirical status of the ultra high-risk (prodromal) research paradigm. Schizophr Bull 33: 661-664.

Chang WC, Chan SS, Hui CL, Chan SK, Lee EH, Chen EY (2015). Prevalence and risk factors for violent behavior in young people presenting with first-episode psychosis in Hong Kong: a 3-year follow-up study. Aust N Z J Psychiatry 49: 914-922.

Coid JW, Ullrich S, Kallis C, Keers R, Barker D, Cowden F et al (2013). The relationship between delusions and violence: findings from the East London first episode psychosis study. JAMA Psychiatry 70: 465-471.

Dean K, Walsh E, Morgan C, Demjaha A, Dazzan P, Morgan K et al (2007). Aggressive behaviour at first contact with services: findings from the AESOP First Episode Psychosis Study. Psychol Med 37: 547-557.

Elbogen EB, Johnson SC (2009). The intricate link between violence and mental disorder: results from the National Epidemiologic Survey on Alcohol and Related Conditions. Arch Gen Psychiatry 66: $152-161$.

Elbogen EB, Van Dorn RA, Swanson JW, Swartz MS, Monahan J (2006). Treatment engagement and violence risk in mental disorders. Br J Psychiatry 189: 354-360.

Fazel S, Langstrom N, Hjern A, Grann M, Lichtenstein P (2009). Schizophrenia, substance abuse, and violent crime. JAMA 301: 2016-2023.

Foley SR, Browne S, Clarke M, Kinsella A, Larkin C, O'Callaghan E (2007). Is violence at presentation by patients with first-episode psychosis associated with duration of untreated psychosis? Soc Psychiatry Psychiatr Epidemiol 42: 606-610.

Foley SR, Kelly BD, Clarke M, McTigue O, Gervin M, Kamali M et al (2005). Incidence and clinical correlates of aggression and violence at presentation in patients with first episode psychosis. Schizophr Res 72: 161-168.

Hutton P, Parker S, Bowe S, Ford S (2012). Prevalence of violence risk factors in people at ultra-high risk of developing psychosis: a service audit. Early Interv Psychiatry 6: 91-96.

IBM Corporation (2013). IBM SPSS Statistics for Windows, Version 22.0. IBM Corporation Armonk: New York. 
Keers R, Ullrich S, Destavola BL, Coid JW (2014). Association of violence with emergence of persecutory delusions in untreated schizophrenia. Am J Psychiatry 171: 332-339.

Klonsky ED, May AM, Saffer BY (2016). Suicide, suicide attempts, and suicidal ideation. Annu Rev Clin Psychol 12: 307-330.

Langeveld J, Bjorkly S, Auestad B, Barder H, Evensen J, Ten Velden Hegelstad W et al (2014). Treatment and violent behavior in persons with first episode psychosis during a 10-year prospective follow-up study. Schizophr Res 156: 272-276.

Large MM, Nielssen O (2011). Violence in first-episode psychosis: a systematic review and meta-analysis. Schizophr Res 125: 209-220.

Marshall C, Denny E, Cadenhead KS, Cannon TD, Cornblatt BA, McGlashan TH et al (2014). The content of attenuated psychotic symptoms in those at clinical high risk for psychosis. Psychiatry Res 219: 506-512.

McGorry PD, Yung A, Phillips L (2001). Ethics and early intervention in psychosis: keeping up the pace and staying in step. Schizophr Res 51: 17-29.

McNiel DE, Eisner JP, Binder RL (2000). The relationship between command hallucinations and violence. Psychiatr Serv 51: $1288-1292$.

Miller TJ, McGlashan TH, Rosen JL, Cadenhead K, Cannon T, Ventura J et al (2003). Prodromal assessment with the structured interview for prodromal syndromes and the scale of prodromal symptoms: predictive validity, interrater reliability, and training to reliability. Schizophr Bull 29: 703-715.

Nielssen O, Large M (2010). Rates of homicide during the first episode of psychosis and after treatment: a systematic review and meta-analysis. Schizophr Bull 36: 702-712.
Rasanen P, Tiihonen J, Isohanni M, Rantakallio P, Lehtonen J, Moring J (1998). Schizophrenia, alcohol abuse, and violent behavior: a 26-year followup study of an unselected birth cohort. Schizophr Bull 24: 437-441.

Spidel A, Lecomte T, Greaves C, Sahlstrom K, Yuille JC (2010). Early psychosis and aggression: predictors and prevalence of violent behaviour amongst individuals with early onset psychosis. Int J Law Psychiatry 33: 171-176.

Steadman HJ, Mulvey EP, Monahan J, Robbins PC, Appelbaum PS, Grisso $T$ et al (1998). Violence by people discharged from acute psychiatric inpatient facilities and by others in the same neighborhoods. Arch Gen Psychiatry 55: 393-401.

Steinert T, Wiebe C, Gebhardt RP (1999). Aggressive behavior against self and others among first-admission patients with schizophrenia. Psychiatr Serv 50: 85-90.

Swanson JW, Swartz MS, Van Dorn RA, Elbogen EB, Wagner HR, Rosenheck RA et al (2006). A national study of violent behavior in persons with schizophrenia. Arch Gen Psychiatry 63: 490-499.

Swartz MS, Swanson JW, Hiday VA, Borum R, Wagner HR, Burns BJ (1998). Violence and severe mental illness: the effects of substance abuse and nonadherence to medication. Am J Psychiatry 155: 226-231.

Winsper C, Singh SP, Marwaha S, Amos T, Lester H, Everard L et al (2013). Pathways to violent behavior during first-episode psychosis: a report from the UK National EDEN Study. JAMA Psychiatry 70: 1287-1293.

Yesavage JA (1982). Inpatient violence and the schizophrenic patient: an inverse correlation between danger-related events and neuroleptic levels. Biol Psychiatry 17: 1331-1337.

Supplementary Information accompanies the paper on the Neuropsychopharmacology website (http://www.nature.com/npp) 